\title{
Erratum
}

\section{Innovative research on the construction of China's youth physical health promotion service system based on sensor technology}

\section{Chenhong Xia}

Institute of Physical Education, Xi'an University of Architecture and Technology, Shaanxi, China

[Journal of Intelligent \& Fuzzy Systems, 37(5) (2019), 6063-6069, 10.3233/JIFS-179189]

https://content.iospress.com/articles/journal-of-intelligent-and-fuzzy-systems/ifs 179189.

The author of Innovative Research on the Construction of China's Youth Physical Health Promotion Service System Based on Sensor Technology, should be listed as Hongxia Chen, and not as Chenhong Xia.

As such, the correct list of author and affiliation data should be:

Hongxia Chen*

Institute of Physical Education, Xi'an University of Architecture and Technology, Shaanxi, China 